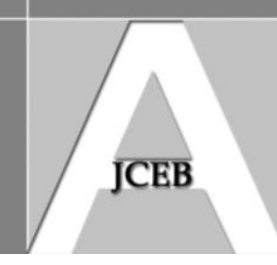

\title{
Analysing the Relationship between New Housing Supply and Residential Construction Costs with the Regional Heterogeneities
}

\author{
Junxiao Liu, (Deakin University, Australia)
}

Kerry London, (RMIT University, Australia)

\begin{abstract}
New housing supply in Australia has been experiencing a low rate of increase in conjunction with a dramatic increase in residential construction costs since the 1990s. This study aims to estimate the relationship between new housing supply and residential construction costs with the regional heterogeneities. Based on a panel error correction model, it can be identified that there is a causal link as well as a significant correlation between new housing supply and construction costs in the Australian sub-national housing construction markets. The model developed in this research assists policy makers to better understand the nature of the supply side of the housing sector and then enact appropriate policies to improve the new housing supply in Australia.
\end{abstract}

Keywords: New housing supply, Residential construction costs, Regional heterogeneities

\section{Introduction}

The capacity of the Australian housing sector to supply has reached a crisis point since the 1990s, during which Australia's urban population increased dramatically (ABS, 2010a). Figure 1 indicates that the annual population growth in Australia exhibited a significant upward trend between 1996 and 2009 while the number of new housing commencements was highly stable. According to the projection of the Australian National Housing Supply Council (NHSC, 2010) in 2010, approximately 3.2 million additional dwellings will be required across Australia in the next 20 years to accommodate a dramatic population growth. Urban economic theory suggests that there should be a long-run convergence between total housing stock and urban population (DiPasquale, 1999). However, it can be inferred from Figure 1 that a divergence between housing supply and urban population has occurred in Australia. The annual report of the Housing Industry Association (HIA, 2010) supported this perspective and stated that a housing shortage of approximately 110,000 emerged in 2009 in Australia and this problem will be exacerbated in the future if the poor performance of the Australian new housing supply is not able to be improved.

An interesting situation along with the low increasing rate of the new housing supply in Australia is that the input producer price indexes (PPI) of housing construction increased by more than $40 \%$ across the Australian states (ABS, 2010b). The input PPI is a measure of the changes in the prices of goods and services purchased by domestic producers for intermediate inputs of products (International Monetary Fund, 2004). Thus, the input PPI related to housing construction is viewed as a measure for the changes in the input cost level of housing production. Conventional economics claims that an increase in the input construction cost reduces new housing output level (Somerville, 1999). However, few empirical studies have investigated whether or not the rises in residential construction costs causally and negatively affect the supply of new housing in Australia.

This paper starts by presenting previous studies on the relationship between new housing supply and residential construction costs. Then, the methodology and the data will be 
described. Finally, the results yielded by the selected econometric model will be utilised for analysis and discussion.

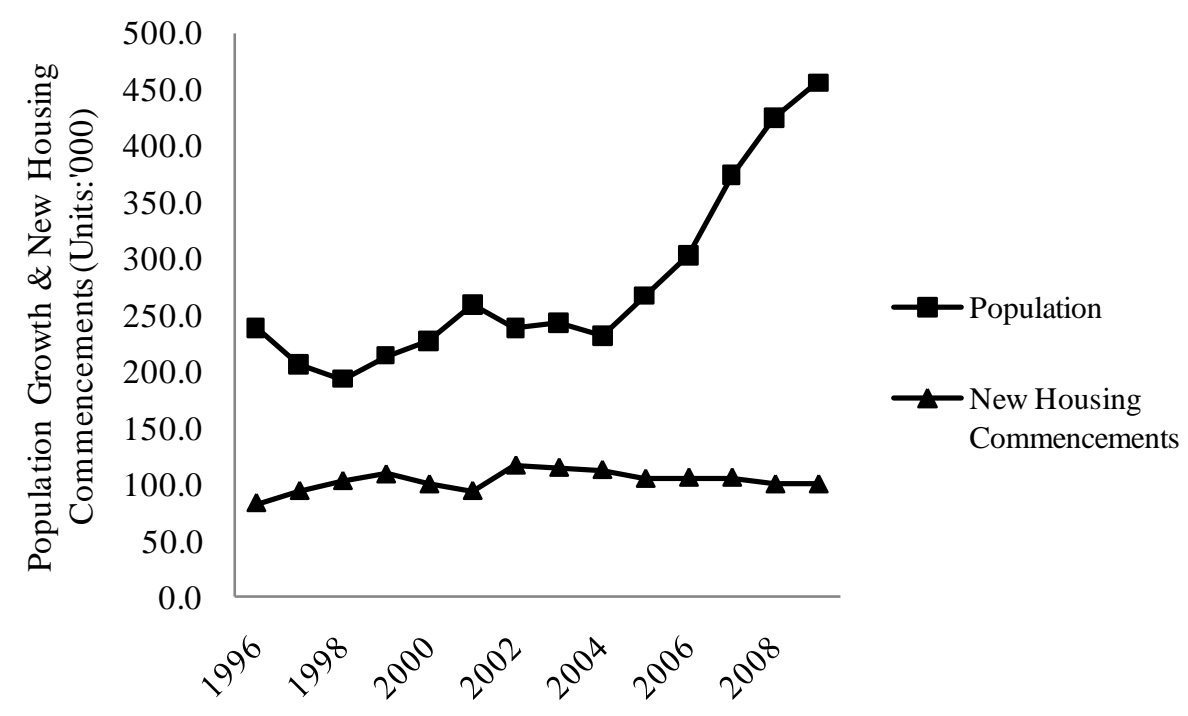

Figure 1 Population growth and new housing commencements in Australia

(Source: ABS, 2010a)

\section{Literature Review}

The studies on new housing supply are less common than that of housing demand. However, the early research with regard to the supply of new housing can be dated back to the 1960 s and the focus is estimating the price elasticity by the reduced-form method. The reduced-form technique is a simple regression approach where house price is a function of the factors in relation to supply and demand.

The early reduced-form study, commenced by Muth (1960), who examines the relationship between new housing outputs and house prices in the US, using national data. The results indicate that there is no correlation between new housing outputs and house prices. Follain (1979) tests the price elasticity of long-run new housing construction applying Muth's (1960) model to national data as well. The results are similar to Muth's (1960) findings, suggesting that new housing starts are totally price inelastic. Nevertheless, it is not possible to conclude, depending upon these two studies (Follain, 1979; Muth, 1960) that the supply of new housing is price inelastic as Muth (1960) and Follain (1979) use national data that has a potential problem in aggregation bias (Stover, 1986). To solve this problem, a function with the cross-sectional data across 61 US metropolitan areas was estimated by Stover's (1986) study, in which new housing supply is significantly related to house prices.

Since the 1980s, there have been a series of empirical studies attempting to model the new housing supply directly. The approaches employed in such research emphasises a more structural method, in which the construction or aggregate supply is deemed to be a function of price and cost factors (DiPasquale, 1999). The theory underpinning these studies is derived from the investment literature and urban spatial theory.

Within the framework of the investment literature, the demand for investment in housing is assumed to be the demand for new construction (Montgomery, 1992). Accordingly, an asset market approach, which views housing investment as a function of economic factors [e.g. 
house prices, the price of output alternative (non-residential deflator) and construction costs], is developed by Poterba (1984) to test the impact of the user costs on the steady state of the housing market. The results indicate that house prices is an essential determinant of new housing construction and the increases in prices of non-residential construction lead to decreases in residential construction. However, Poterba (1984) found that there is no significant relationship between construction costs and new housing supply.

The model proposed by Poterba (1984) pursues the long-run equilibrium relationships among new housing supply, house prices and cost factors. However, the interrelationship between the variables within a short-run context is ignored. Topel and Rosen (1988) identified this point and developed a model where new housing supply is a function of house prices and a vector of cost factors. The results show that the long-run supply elasticity of price is 3.0 but the short-run elasticity is only 1.0. In short, the supply of new housing in the US is price elastic. Topel and Rosen's (1988) model yields a result similar to Poterba's (1984) findings, which suggest that the impact of construction cost on new housing supply is not significant.

Although the investment-based models (Poterba, 1984; Topel and Rosen, 1988) have contributed to the literature, advocates of the urban-spatial theory still criticise these studies because all of them ignore an important issue - the input of land. In reality, Poterba (1984) acknowledged the importance of land input in housing supply research but omitted it in his model due to a lack of data.

The urban spatial theory is a theoretical system which assumes that total housing stock equals urban population and land issues maintain an important role in new housing production (DiPasquale, 1999). One valuable piece of housing supply work on the basis of urban spatial theory is the research by DiPasquale and Wheaton (1994). This study produces an equation where new housing supply is a function of house prices, land prices, construction costs and lagged housing stock. By estimating this function, the price elasticity of housing stock and the price elasticity of new housing construction range from 1.2 to 1.4 and 1.0 to 1.2 respectively. However, DiPasquale and Wheaton (1994) can not identify a significant linkage between construction costs and new housing construction.

As described previously, the empirical research on new housing supply shared a problem in estimating the interrelationship between new housing supply and construction costs. Therefore, Somerville (1999) develops an hedonic construction cost series with an entirely new set of micro-data on housing construction to examine the link between new housing outputs and residential construction costs across the metropolitan areas of the US. The empirical results indicate that the housing starts in the US are cost elastic and construction cost is endogenous in the new housing supply function. The possible reason for the poor performance of the housing supply studies of housing starts and construction costs is a bias in the commercial cost indexes used by the previous research (Somerville, 1999).

This literature review demonstrates that some empirical studies (DiPasquale \& Wheaton, 1994; Poterba, 1984; Topel \& Rosen, 1988) have attempted to uncover the linkage between new housing supply and residential construction costs since the 1980s. However, the researchers fail to identify a significant relationship between these two variables. In 1999, Somerville (1999) successfully discovered this correlation and claimed that the possible reason for the poor performance of the previous studies is the bias in the data. In addition, it can be identified from the existing housing supply literature that the 'regional heterogeneity' has not been empirically considered in the past research, leading to an critical assumption that omitting the 'regional heterogeneities' could be another reason for the failure of the previous models (DiPasquale \& Wheaton, 1994; Poterba, 1984; and Topel \& Rosen, 1988). This paper will contribute to the literature by exploring the relationship between new housing supply and residential construction costs with the regional heterogeneities.

Liu, J and London, K (2011) 'Analysing the relationship between new housing supply and residential construction costs with the regional heterogeneities', Australasian Journal of Construction Economics and Building, 11 (3) 58-67 


\section{Significance of the Regional Heterogeneity}

The literature review suggests that construction cost is a key determinant of new housing supply. However, the sub-national or regional housing markets are segmented and can be influenced by a series of variables other than costs changes, such as policies, culture, race, education and even gender composition of local populations (Tu, 2003). These factors result in regional variations, which are also known as the 'regional heterogeneities'. The majority of the factors that trigger the regional heterogeneities (e.g. culture, race and education) are difficult to observe in empirical research, however they can stay constant over time to effectively affect the demand and the supply sides of the housing sector (Reed, 2001). Thus, modeling the housing markets on a regional level without regional heterogeneities is not realistic.

The study conducted by Tu (2000) discovered that the Australian regional housing markets are segmented and they are mainly determined by local factors varied by regions. In simple terms, the 'heterogeneities' across the regions maintain an active role in the sub-national housing markets in Australia. As a result, the regional heterogeneities are significant to the study regarding the Australian sub-national housing sector.

\section{Methodology}

Theoretically, the entity fixed-effect models of the panel econometric techniques not only capture the time-series effects, but also allow for 'the effects of those omitted variables that are specific to individual cross-sectional units but stay constant over time' (Hsiao, 2003, p. 30). In other words, the panel econometric models can quantify the effects specific to the heterogeneities within a cross-sectional unit (e.g. regional markets) across periods (Greene, 2000).

To investigate the causal link and correlation between new housing supply and residential construction costs with regional heterogeneities, a panel error correction model (ECM) will be employed in this study. The ECM is a regression model with a cointegration and error correction term. It is useful for identifying the Granger causality and any correlation between variables (Dinda \& Coondoo, 2006; Luo et al., 2007). Two tests must be conducted before constructing the panel ECM, one is the panel unit root test and the other is the panel cointegration test.

\section{Panel Unit Root Tests: IPS test}

The unit roots tests are an important step for econometric modeling and they are utilised to examine the stationarity of the data. It is argued that the regression will be spurious if the data imported are non-stationary (Granger \& Newbold, 1974). The method used in this paper to test the unit roots is the IPS test.

The IPS test is proposed by Im et al. (Im, Pesaran and Shin) $(1997 ; 2003)$ in 1997. The main equation of the IPS test is expressed in Eq. (1).

$$
\Delta y_{i, t}=\delta_{i} y_{i, t-1}+\alpha_{i}+\varepsilon_{i, t}(i=1,2, \cdots, N ; t=1,2, \cdots, T)
$$

The null and alternative hypotheses of the IPS test are defined as:

$$
\begin{aligned}
& H_{0}: \delta_{i}=0(i=1,2, \cdots, N) \\
& \qquad H_{1}: \delta_{i}<0(i=1,2, \cdots, N), \delta_{i}=0\left(i=N_{1}+1, N_{1}+2, \cdots, N\right)
\end{aligned}
$$


The $\varepsilon_{i, t}$ are serially auto-correlated with different serial correlation properties across units. A group-mean Lagrange multiplier (LM) statistic is used by Im et al. (1997) to test the null hypothesis in Eq. (2). This LM-statistic is computed by the regression shown as follows:

$$
\Delta y_{i, t}=\delta_{i} y_{i, t-1}+\sum_{L=1}^{p_{i}} \theta_{i, L} y_{i, t-L}+\alpha_{i}+\varepsilon_{i, t}, \quad t=1,2, \ldots T \text {. }
$$

Im et al. (1997) defines

$$
\overline{\operatorname{LM}}_{N, T}=N^{-1} \sum_{i=1}^{N} \operatorname{LM} M_{i T}\left(p_{i}, \theta_{i}\right)
$$

Then the values of $E\left[\overline{L M}_{i, t}\left(p_{i}, 0\right) \mid \delta_{i}=0\right]$ and $\operatorname{Var}\left[\overline{L M}_{i, t}\left(p_{i}, 0\right) \mid \delta_{i}=0\right]$ are obtained by Im et al. (1997). Under these assumptions, Im et al. (1997) concludes that:

$$
\Psi \frac{}{L M} \Rightarrow N(0,1)
$$

Im et al. (1997) also employs a group-mean $t$-bar statistic to test the unit roots of the panel data. Applying a Monte Carlo Study, Im et al. (1997) demonstrates the finite sample property of the IPS test and identifies that the IPS test under the small sample has a better performance than other panel unit root tests.

\section{Panel Cointegraton Tests}

The panel cointegration test developed by Pedroni (1999) will be selected in this study. Pedroni's (1999) test is an EG-based (Engle-Granger) cointegration test, in which the following models of the cointegrated regressions are considered.

$$
y_{i, t}=\alpha_{i}+\delta_{i} t+x_{i, t} \beta_{i}+\mu_{i, t}, \quad(i=1, \ldots, N, t=1, \ldots, T)
$$

where $\beta_{i}=\left(\beta_{1 i}, \beta_{2 i}, \ldots, \beta_{M i}\right)$ and $x_{i, t}=\left(x_{1 i, t}, x_{2 i, t}, \ldots, x_{M i, t}\right)$. The system expressed as Eq. (6) allows for heterogeneity in the panel. As a result, heterogeneous coefficients, fixed effects and individual specific deterministic trends are all permitted. Moreover, $y_{i, t}$ and $x_{i, t}$ are integrated process of order one for all $i$.

Pedroni (1999) builds up a $H_{0}$, defining $z_{i, t}=\left(y_{i, t}, x_{i, t}^{\prime}\right), \xi_{i, t}^{\prime}=\left(\xi_{i, t}^{y}, \xi_{i, t}^{x}\right)$, and $z_{i, t}=z_{i, t-1}+\xi_{i, t}$, where the process $\xi_{i, t}^{\prime}$ satisfies

$$
\frac{1}{\sqrt{T}} \sum_{t=1}^{T r} \xi_{i, t} \Rightarrow B_{i}\left(\Omega_{i}\right) \text { for all } i \text { as } \mathrm{T} \rightarrow \infty
$$

Here $B_{i}\left(\Omega_{i}\right)$ is a vector Brownian motion with asymptotic covariance $\Omega_{i}$ in which $\Omega_{22}$ is non-singular. The $B_{i}\left(\Omega_{i}\right)$ is utilised to be defined on the same probability space for all $i$ and $E\left(\xi_{i, t}, \xi_{j, s}^{\prime}\right)=0$ for all $i \neq j$ and then for all $s, t$.

Accordingly, seven panel cointegration statistics are derived by Pedroni (1999), of which four tests belong to the first categories that are defined as within-dimension-based statistics. In the first category, the four tests depend on a variance ration statistic, a non-parametric 
Philips and Perron type $\rho$-statistic, a non-parametric Philips and Perron type $t$-statistic and a parametric ADF-based test respectively. Regarding the second category, which is defined as the between-dimension-based statistics, two of the three tests are non-parametric corrections while the third is a test of the ADF. The tests in the second category are based on a group mean approach (Pedroni, 1999).

\section{Panel Error Correction Model}

Once the pairwise cointegration between two variables has been identified, the next step in the Engle-Granger methodology is to model the short-run variations of the variables, which can be done by estimating the ECM (Dinda \& Coondoo, 2006). The ECM was first introduced by Sargan (1964) in the 1960s and systematically developed by Davidson et al. (1978) in the 1970s. However, the ECM was widely promoted by Engle and Granger (1987) in the 1980s. According the ECM methodology, the panel ECM is written:

$$
\begin{gathered}
\Delta Y_{i, t}=\mu_{i}+\beta_{i} \Delta X_{i, t}+\phi_{i} e \operatorname{cm}_{i, t-1},(i=1,2,3 \ldots, N ; t=1,2,3 \ldots, T) \\
e c m_{i, t-1}=Y_{i, t-1}-\alpha_{0}-\alpha_{1} X_{i, t-1}
\end{gathered}
$$

where $\Delta Y_{i, t}$ and $\Delta X_{i, t}$ represent the data panel $Y_{i, t}$ and $X_{i, t}$ at the first difference; $\mu_{i}$ and $\beta_{i}$ denote the regression parameters; the symbol $\phi_{i}$ stands for the rapidity of adjusting to equilibrium and they are expected to have negative values; and the $e c m_{i, t-1}$ represents the error correction term, in which the $\alpha_{0}$ is the constant item and the $\alpha_{1}$ stands for the longterm elasticity. The error correction term can be derived from the residual generated by a simple regression of two variables. The panel ECM in this study will be estimated by a seemingly unrelated regression (SUR), which is able to 'address problems associated with the presence of cross-sectional dependency among the series in the panel' (Holmes, 2007, p. 3).

\section{Data Collection}

For the purpose of estimating a panel ECM, the new housing commencements (NHC) and the input PPI (IPPI) of housing construction of the Australian six states (excluding Australian Capital Territory and Northern Territory) will be selected. The data on the new housing commencements are published in Building Activity Australia in the ABS, measuring the number of the new housing commenced for construction (ABS, 2010b). The input PPI of housing construction is one type of the producer price indexes used to measure the prices of goods or services purchased by domestic producers for intermediate inputs of housing construction (ABS, 2010c).

The reason for excluding the two territories in the model is a lack of housing construction input PPI of the Nothern Territory and the Australian Capital Territory. The report of the ABS (2010b) on the Australian Social Trends claimed that the data for national total on the input PPI of house construction are a weighted average of six states. As a result, modelling the new housing supply and construction costs for Australia without the data on two territories is acceptable. All the data imported into the panel ECM in next analytical section are transformed to natural logarithms.

\section{Analysis and Discussion}

Likewise the time-series ECM, the prerequisite of constructing the panel ECM is that the data used must be stationary. Table 1 reports the results of the IPS unit root tests and it indicates that the data are integrated of the order one, i.e. I (1). 


\begin{tabular}{|l|c|c|c|l|c|c|c|c|}
\hline & \multicolumn{4}{|c|}{ Level } & \multicolumn{3}{c|}{ First Difference } & Results \\
\hline & \multicolumn{2}{|c|}{ Model Specification (Lags) } & Stat. & $p$-value & Model Specification (Lags) & Stat. & $p$-value \\
\hline In(NHC) & Individual Intercept \& Trend & -0.97 & 0.17 & Individual Intercept (1) & -3.00 & 0.00 & $I(1)^{\star \star *}$ \\
\hline In(IPPI) & Individual & Intercept \& Trend & -0.74 & 0.23 & Individual Intercept (1) & -5.81 & 0.00 & $I(1)^{\star \star *}$ \\
\hline
\end{tabular}

Table 1 Summary of the IPS unit root test results

Notes: ** and *** denote the $95 \%$ and $99 \%$ significance level

The second step for formulating the ECM is to identify the cointegration relationship. As mentioned in Methodology, the Pedroni test will be conducted. Table 2 summarises the Pedroni test results associated with the selected variables. The results suggest that there is cointegration between the new housing commencements and the input PPI.

\begin{tabular}{|l|c|c|c|c|c|c|}
\hline & Model Specification (Lags) & $\begin{array}{c}\text { Panel } \\
\text { ADF-Stat. }\end{array}$ & P-values & $\begin{array}{c}\text { Weighted Panel } \\
\text { ADF-Stat. }\end{array}$ & $\begin{array}{c}\text { P-values } \\
\text { (weighed) }\end{array}$ & Results \\
\hline In(NHC) (D.V.) & Individual Intercept (1) & -1.74 & 0.04 & -1.80 & 0.04 & Y \\
\hline \multirow{2}{*}{ In(IPPI) (I.V.) } & Individual Intercept \& Trend (1) & -1.58 & 0.05 & -1.78 & 0.04 & Y \\
\hline
\end{tabular}

Table 2 Summary of the Pedroni cointegration test results

Notes: D. V. denotes the dependent variable and I. V. denotes the independent variable

As cointegration is found, the panel ECM can be constructed to uncover the nature of the target relationship. The model displayed as Eq. (10) is the panel ECM composed of the new housing commencements and the input PPI. Table 3 shows the $t$-statistics and the $p$-values of the independent variables of the panel ECM, all of which indicate that the coefficients of the independent variables (IPPI) are significant.

$$
\left\{\begin{array}{l}
D\left(N H C_{N S W, t}\right)=0.0725-1.0420 * D\left(I_{P P I_{N S W, t}}\right)-0.6277 * e c m_{N S W, t-1}+00396 \\
D\left(N H C_{V I C, t}\right)=0.0372-1.9925 * D\left(I P P I_{V I C, t}\right)-0.5320 * e c m_{V I C, t-1}+0.0396 \\
D\left(N H C_{Q L D, t}\right)=0.0303-2.6834 * D\left(I P P I_{Q L D, t}\right)-0.5053 * e c m_{Q L D, t-1}+0.0396 \\
D\left(N H C_{S A, t}\right)=0.0630-1.7068 * D\left(I P P I_{S A, t}\right)-0.5732 * e c m_{S A, t-1}+0.0396 \\
D\left(N H C_{W A, t}\right)=0.0021-1.2247 * D\left(I P P I_{W A, t}\right)-0.5069 * e c m_{W A, t-1}+0.0396 \\
D\left(N H C_{T A S, t}\right)=0.0600-2.0529 * D\left(I P P I_{T A S, t}\right)-0.6716 * e c m_{T A S, t-1}+0.0396
\end{array}\right.
$$

Based on the cointegration tests and the panel ECM (Eq. 10), it can be concluded that there is a causal link between the new housing commencements and the input PPI of housing construction across the Australian six states. As claimed by Johansen (1988), the Granger causality exists in at least one direction between two variables if they are co-integrated. In the Pedroni cointegration tests and the panel ECM, the NHC is the dependent variable and the IPPI is the independent variable. Hence, the input PPI Granger-causes the new housing construction on a regional level in Australia. Furthermore, the coefficients of the input PPI in the panel ECM are all significant and negative, which indicate that the increasing trends of the new housing commencements in six states were significantly depressed by the dramatic

Liu, J and London, K (2011) 'Analysing the relationship between new housing supply and residential construction costs with the regional heterogeneities', Australasian Journal of Construction Economics and Building, 11 (3) 58-67 
increases in the housing construction input PPI. This finding complies with the conventional economic theory discussed in Introduction.

\begin{tabular}{|c|c|c|}
\hline & $\boldsymbol{t}$-statistics & $p$-values \\
\hline$I P P I_{N S W, t}$ & -4.59 & 0.00 \\
\hline$I P P I_{V I C, t}$ & -6.57 & 0.00 \\
\hline$I P P I_{Q L D, t}$ & -4.15 & 0.00 \\
\hline$I P P I_{S A, t}$ & -2.64 & 0.01 \\
\hline$I P P I_{W A, t}$ & -2.85 & 0.01 \\
\hline$I P P I_{T A S, t}$ & -4.28 & 0.00 \\
\hline
\end{tabular}

Table $3 \mathrm{t}$-statistics and $\mathrm{p}$-values of the coefficients of the independent variables

According to the coefficients in Eq. (10), the new housing commencements are sensitive to the changes in the input PPI of the Australian six states. Specifically, the supplies of new housing in Queensland and Tasmania are more sensitive to the construction cost fluctuations than that of other four states. In New South Wales, Victoria, South Australia and Western Australia, the supply elasticities of the construction costs are similar, ranging from 1.22 to 1.99. Moreover, the first coefficients of the six equations in Eq. (10) indicate that the regional heterogeneities across the sub-national housing markets in Australia significantly affect the relationship between the Australian new housing supply and residential construction costs. These results support the assumptions on the importance of the regional heterogeneity addressed previously.

\section{Conclusions}

This study has empirically estimated the relationship between the supply of new housing and construction costs in Australia with regional heterogeneities. Depending upon the panel ECM and the tests for the panel unit roots and the panel cointegration, a causal link affected by the regional heterogeneities has been identified from the input PPI to the new housing commencements in Australia. The coefficients of the variables in relation to housing construction costs in the panel ECM are significant and negative, indicating that the increasing trends of the Australian new housing supply had been significantly depressed by the residential construction costs. It can be further discovered from the empirical evidence that the new housing outputs in Queensland and Tasmania are more sensitive to construction cost changes than New South Wales, Victoria, South Australia and Western Australia. The essential role of regional heterogeneities and the significant correlation validate the assumption that omitting regional heterogeneities could be the reason for the failure of the previous research in establishing a linkage between new housing supply and construction costs. The model developed in this study is suited for investigating the residential construction sector within a comprehensive context, and it provides policy makers with valuable information to better estimate market development.

The overall findings in this paper imply that construction costs and local issues (e.g. political and demographic factors) are undoubtedly key determinants of the poor performance of the Australian new housing supply. Accordingly, how to control the cost inflation in the 
residential construction sector will be one of the challenges for the state governments, to deal with the imbalance between dramatic population growth and low housing supply across Australia.

\section{References}

ABS (2010a) Australian Social Trends, available at: http://www.abs.gov.au/AUSSTATS labs@.nsf/DetailsPage/4102.0Jun\%202010?OpenDocument (accessed 28 August 2010)

ABS (2010b) Building activity, Australia, available at: http://www.ausstats.abs.gov.au/aus stats//ABS@Archive.nst/0/0EF2CDFE267B47ADCA25775F0016E358/\$File/87520034.xls (accessed 28 August 2010)

Davidson, J.E.H., Hendry, D.F., Srba, F. and Yeo, S. (1978) 'Econometric modelling of the aggregate time-series relationship between consumers expenditure and income in the United Kingdom', Economic Journal, 88 (352), 661-692

Dinda, S. and Coondoo, D. (2006) 'Income and emission: A panel data-based cointegration analysis', Ecological Economics, 57 (2), 167-181

DiPasquale, D. (1999) 'Why don't we know more about housing supply?', Journal of Real Estate Finance and Economics, 18 (1), 9-23

DiPasquale, D. and Wheaton, W.C. (1994) 'Housing market dynamics and the future of housing prices', Journal of Urban Economics, 35 (1), 1-27

Engle, R.F. and Granger, C.W.J. (1987) 'Co-integration and error correction: representation, estimation, and testing', Econometrica, 55 (2), 251-276

Follain, J.R. (1979) 'The price elasticity of the long-run supply of new housing construction', Land Economics, 55 (2), 190-199

Granger, C.W.J. and Newbold, P. (1974) 'Spurious regression in econometrics', Journal of Econometrics, 2 (2), 111-120

Greene, W.H. (2000) Econometric analysis, 4th Edn. Prentice-Hall, New Jersey, US

Holmes, M.J. (2007) 'How convergent are regional house prices in the United Kingdom? Some new evidence from panel data unit root testing', Journal of Economic and Social Research, 9 (1), 1-17

Housing Industry Association (2010) Australia's population growth, available at: http://ec onomics.hia.com.au/media/Australia's\%20Population\%20Growth.pdf (accessed 31 August 2010).

Hsiao, C. (2003) Analysis of panel data, Cambridge University Press, Cambridge, UK

Im, K.S., Pesaran, M.H. and Shin, Y. (1997) Testing for unit roots in heterogeneous panels, Mimeo, Department of Applied Economics, University of Cambridge

Im, K.S., Pesaran, M.H. and Shin, Y. (2003) 'Testing for unit roots in heterogeneous panels', Journal of Econometrics, 115 (1), 53-74

International Monetary Fund (2004) Producer price index manual: Theory and practice, IMF, Washington DC, US

Johansen, S. (1988) 'Statistical analysis of cointegration vectors', Journal of Econometric Dynamics and Control, 12 (2), 231-254

Luo, Z.Q., Liu, C. and Picken, D. (2007) 'Housing price diffusion pattern of Australia's state capital cities', International Journal of Strategic Property Management, 11 (4), 227-242

Montgomery, C. (1992) 'Explaining home investment in the context of household investment in residential housing', Journal of Urban Economics, 32 (3), 326-350 
Muth, R. (1960) The demand for non-farm housing, in Harberger, A. C. Eds., The Demand for Durable Goods, The University of Chicago Press, Chicago, US

NHSC (2010) National Housing Supply Council: 2nd State of Supply Report, available at: http://www.fahcsia.gov.au/sa/housing/pubs/housing/national_housing_supply/Documents/St ateofSupplyReport_2010.pdf (accessed 25 May 2011)

Pedroni, P. (1999) 'Critical values for cointegration tests in heterogeneous panels with multiple regression', Oxford Bulletin of Economics and Statistics, 61 (4), 653-670

Poterba, J.M. (1984) 'Tax subsides to owner occupied housing: An asset market approach', Quarterly Journal of Economics, 99 (4), 729-752

Reed, R. (2001) 'The significance of social influences and established housing values', PRRES 2001: Refereed Proceeding of the 7th Pacific Rim Real Estate Society Conference, Adelaide, Australia

Sargan, J.D. (1964) 'Wages and prices in the United Kingdom: A study in econometric methodology', in: Wallis, K. F. and Hendry, D. F. Eds., Quantitative Economics and Econometric Analysis, Basil Blackwell, Oxford, UK

Somerville, C.T. (1999) 'Residential construction costs and the supply of new housing: Endogeneity and bias in construction cost indexes', Journal of Real Estate Finance and Economics, 18 (1), 43-62

Stover, M.E. (1986) 'The price elasticity of the supply of single-family detached urban housing', Journal of Urban Economics, 20 (3), 331-340

Topel, R. and Rosen, S. (1988) 'Housing investment in the United States', Journal of Political Economy, 96 (4), 718-740

Tu, Y. (2000) 'Segmentation of Australian housing markets: 1989-98', Journal of Property Research, 17 (4), 311-327

Tu, Y. (2003) Segmentation, adjustment and disequilibrium, in: O' Sullivan, T. and Gibb, K. Eds., Housing Economics \& Public Policy, Blackwell Science, UK 